\title{
Positivism Against Constructivism: A Network Game to Learn Epistemology
}

\author{
Hélène Hagège ${ }^{1, *}$, Christopher Dartnell ${ }^{2}$, and Jean Sallantin ${ }^{2}$ \\ ${ }^{1}$ Université Montpellier II, Laboratoire Interdisciplinaire de Recherche en Didactique \\ Education et Formation, CC 077, place Eugène Bataillon, 34095 Montpellier cedex 5, France \\ hhagege@univ-montp2.fr \\ ${ }^{2}$ Laboratoire d'Informatique de Robotique et de Microélectronique de Montpellier, UMR 5506, \\ 161 rue Ada, 34392 Montpellier Cedex 5, France \\ dartnell, sallantinalirmm.fr
}

\begin{abstract}
As mentioned in French secondary school official texts, teaching science implies teaching scientific process. This poses the problem of how to teach epistemology, as traditional science teaching is mostly dogmatic and based on contents. Previous studies show that pupils, science students and teachers mostly own positivist and realist spontaneous conceptions of science and scientific discovery. Here, we present the evaluation of the didactic impact of a network game, Eleusis+Nobel, on third year biology students who aim at becoming teachers. This cards game, based on a Popperian epistemology, has been designed to reproduce the scientific discovery process in a community. In the limits of our study, results obtained with classical social psychology tools indicate that students who played this game specifically assimilated the subjective dimension of knowledge and the role of the community in their conception of science, on the contrary to negative control students, who did not play.
\end{abstract}

Keywords: epistemology, positivism, constructivism, science education.

\section{Introduction}

Scientific discovery is a complex process including psychological, social and historical dimensions. As far as the cognitive psychological dimension is concerned, research made an advance since both science products (concept or knowledge) and process (experimental design and evidence evaluation skills) have been integrated in the descriptive framework of Scientific Discovery as Dual Search [13]. Simulated science discovery tasks have then been focalised on domain specific discoveries integrating science process consideration (for a review see [21]). However, few simulations take into account the social dimension of scientific discovery, which is considered as central by epistemologists (e.g. [14]). Here, we are interested in one of those: Eleusis+Nobel network game $(\mathrm{E}+\mathrm{N} ;[5,6])$.

\footnotetext{
* Corresponding author.

V. Corruble, M. Takeda, and E. Suzuki (Eds.): DS 2007, LNAI 4755, pp. 91-103, 2007.

(c) Springer-Verlag Berlin Heidelberg 2007
} 


\subsection{Problematics}

All these interesting developments raise the question of their social utility: what do people who take part in such simulations really learn? Are they able to transfer what they learn to their conception of science? We try here to provide elements to answer these questions, which have not yet occurred, as far as we know.

In other words, the matter is to know whether such simulations can be used as tools to teach epistemology. In France, all secondary science teachers enter a classroom very soon, without having entered a research laboratory. That is to say, they do not know what science looks like. New French official texts contain the explicit obligation for them to teach science process [3], although traditional education always put the emphasis on contents. Given the little practical place devoted to epistemology during the formation of teachers, and the contradiction of teaching epistemology in a dogmatic way, we were willing to evaluate alternative ways of teaching. We propose here an evaluation of the impact of $\mathrm{E}+\mathrm{N}$ game on third year general biology students, who aim at becoming secondary biology teachers.

\subsection{E+N Game}

$\mathrm{E}+\mathrm{N}$ is a card game inspired from Abott's game [9], and was designed in collaboration with cognitive scientists [5] to simulate scientific discovery and to study the players' strategies during a collective process of proof and refutations.

Players have to discover a set of hidden rules, each determining the valid card sequences that can be formed during the game. A hidden rule is a set of clauses as "A red card can be followed by a black card, and a black card by a red card" using the colour and the form of a card (red, heart ...) and/or its rank (ace, figure, pair...).

Each player has access to private experimentation spaces corresponding to each hidden rule, in which he/she can play cards and form sequences which are classified as true or false by the hidden rule. Players can publish their own theories explaining hidden rules, read the ones submitted by other players and possibly refute them when they find a sequence which is irrelevant with what was published. This game is based on a Popperian conception of science, where validation goes through conjectures and refutations. Publications and refutations are sanctioned by the following score system. A player scores $\mathrm{n}$ points when publishing a theory, and n' points by refuting an existing one, in which case the publisher of this theory looses n' points. The game ends after a fixed duration (two or three hours), and the player with the highest score wins the Nobel Prize. The ratio n/n' can be changed from one game to another to study the variations in player's strategies. We refer to previous paper [6] for a more detailed description of the game's rules and interface.

\subsection{Theoretical Frame of the Study}

In science education and epistemology, a constructivist vision of building knowledge has been developed (e.g. $[8,14,19])$, to which a majority of research workers in these domains seem to adhere [15]. According to constructivism, all knowledge is linked to a subject who knows [8]. So, its profound nature is subjective. Thus conviction, point 
of views and beliefs are part of science and learning $[1,14]$. On the other hand, all knowledge is issued from a construction process. This process consists in qualitative reorganisation of initial knowledge structure [17], and can be assimilated to change of conceptions [19]. Conceptions play an organisational role in thinking and learning [19], but affects and values also do [10].

Here, we refer to personal epistemology as a system of interacting attitudes related to knowledge construction objects (such as error, science...). Attitudes are composed of a cognitive and an affective component (i.e. conception of an object, and affective relation to this object; [11]). They interact together and norms and associated values emerge from this epistemic attitudes system [10]. Norms are rules telling how the subject should behave in a particular situation and values consist in general principles which justify the corresponding norms.

Most studies on epistemology learning and teaching concern conceptions, i.e. what we call the cognitive component of attitudes. Science teachers and students do not own constructivist spontaneous science conceptions (e.g. [2, 16, 20]). For instance, to future biology teachers, knowledge is an "external truth that can be discovered through observation, discussion, sense-making" and also a collection of additive facts [16]. In that sense, experiment can constitute a supreme arbitrary to verify theories. This naïve, positivist labelled epistemology also contains a realist view, given which the world is intimately knowledgeable (in opposition to an idealist conception), so that scientific knowledge tells us about a truth: the world as it is. This positivist and realist vision is coherent with naïve [18] and traditionalist [4] epistemologies evaluated by other authors, in the sense that knowledge would be composed of information units which are progressively added, thus allowing knowledge progress. In fact, secondary teachers define teaching as a "maximum information transfer" and learning as an "every information absorption" $[2,20]$.

In the following, we evaluate $\mathrm{E}+\mathrm{N}$ playing impact on science conceptions, values, and to a less extent, affects. We used the standard pre-test/post-test procedure. The test was mostly composed of a Likert-type scale and of Osgood's semantic differentiators (OSD). Values are considered to be implicit in all adjectives, but some of those explicitly refer to values, such as good and beautiful. Affects correspond to pleasure and pain domain. Conceptions are here considered as moving from a positivist and realist extremity to an idealist and constructivist one. One has to notice that we refer to philosophical corresponding notions, to be able to characterise students' undifferentiated epistemology. These students initially had no deep thought about scientific process. E+N implements the Popperian intersubjective construction of objectivity concept, which is a central point of what became constructivism. That is why we expected $\mathrm{E}+\mathrm{N}$ game to favour constructivist epistemology development.

\section{Methodology}

\subsection{Procedure and Subjects}

The study has been realized in South France, in the University Montpellier II. In January 2007, 43 third year general biology students filled up the initial test (= initial experiment). All these students aimed at becoming life and earth science secondary 
school teachers and were registered to follow the same science education and epistemology courses. One and a half month later, 14 of them (=Pl for Players) played $\mathrm{E}+\mathrm{N}$ then filled up the final test (6 days later), whereas 14 others $(=N C$ for Negative Controls) filled up the final test without having played. The final test corresponds to the initial test plus some additive questions. For both Pl and NC groups, the initial experiment is called the pre-test and the final one the post-test. Players have been told that this game mimics scientific discovery as it occurs - in community. During the game, Pl was mixed together with 24 other students and the whole sample was split into 16 teams of 2 or 3 players. All 16 computers were in the same room. The game lasted 2 hours and the winner team won a $1 \mathrm{~kg}$ candy box (the Nobel Price). There was a non desired function in the program: players could refute themselves and win points whereas they should normally have lost the points gained during publication. Particularly, two teams concentrated on this strategy and this provoked a revolt atmosphere at the end of the session.

\subsection{Measuring Tools}

Classical tools of socio-psychology have been used for this study. A Likert-type scale is a group of propositions which measure the same psychometric variable. Subjects have to indicate their degree of agreement for each proposition (see Appendix 1). For OSD relative to a term, subjects have to choose a position between two opposite adjectives, depending on the one that best describes the term from their point of view. For each scale and each individual, we calculated a score, which corresponds to the average answer to the scale's items.

The pre-test is composed of a questionnaire and an OSD series. The questionnaire aims at assessing positivist and realist conceptions in opposition with constructivist and idealist ones. It is composed of two subscales: "Realism and truth status" (RTS) and "Research worker's status" (RWS) subscales (Appendix 1). OSD were designed to evaluate conceptions ( $\mathrm{C} 1$ to $\mathrm{C} 3$ scores), values (V1 to V4 scores) and affects (A score) related to five terms, considered as epistemic objects (Appendix 2).

The post-test contains additional OSD, relative to conceptions of proof and refutation (Appendix 3) and two open questions: "1) Give 3 terms you associate to the communication of results in a scientific community" and "2) Give 3 terms you associate to scientific discovery". We respectively expected the occurrence of publication and refutation terms specifically for the Pl group. Since these parts did not appear in the pre-test, we are not able to observe any change in conceptions. Consequently, the results are only indicative.

\subsection{Results Analysis}

Data were collected, reported in $\operatorname{Excel}^{\mathrm{R}}$ and analyzed with $\mathrm{SPSS}^{\mathrm{R}}$ 9.0 software. Nonparametric tests were used to compare item per item (Wilcoxon signed ranks test on paired samples ${ }^{*}$ and Mann-Whitney test on independent samples). Independent or paired samples" T-tests allowed scores comparison. ("for pre-test/post-test comparison in a given subpopulation $-\mathrm{Pl}$ or $\mathrm{NC}$ ) 


\section{Results}

\subsection{Homogeneity of Pl and NC Subpopulations at the Pre-test}

To verify that $\mathrm{Pl}$ and $\mathrm{NC}$ subpopulations were comparable, we first looked at social variables (Table 1A). Both subpopulations were significantly the same average age and were composed of the same number of males and females. Concerning parents' socio-professional category, we cannot know much since the majority of subjects answered other, although our sampling do not seem to be biased relatively to professions linked to scientific research or scientific education.

Table 1. Comparison of Pl and NC Subpopulations Pre-test Variable Means and Average Variable Means for Pooled Pl and NC.

sd : standard deviation

for T-test, $\mathrm{df}=26$

$t$ is obtained after an independent samples T-test

A) Social Variables

\begin{tabular}{llll}
\hline & age & sexe & spc of parents \\
\hline $\mathbf{t}(\mathbf{P I} \boldsymbol{v s} \mathbf{N C})$ & -1.381 & $0.000^{\mathrm{a}}$ & $-0.801^{\mathrm{a}}$ \\
Mean $(\mathbf{P l}+\mathbf{N C}) ;(\mathbf{s d})$ & $20.86(1.11)$ & $1.29(0.46)$ & $5.11(1.64)$ \\
\hline
\end{tabular}

spc : socio-professional category

a concerning these ordinal variables, Wilcoxon test also leads to the conclusion of population homogeneity

sex : 1 female, 2 male

spc of parents : 1 scientific education, 2 scientific research , 3 agriculture, 4 industry, 5 health and 6 other

\section{B) Pre-test Scores}

\begin{tabular}{lllllllllll}
\hline Score & RTS & RWS & V1 & V2 & V3 & V4 & A & C1 & C2 & C3 \\
\hline t (PI vs NC) & -0.245 & 0.217 & $2.664 *$ & 0.137 & 0.113 & 1.168 & 0.437 & -0.303 & -0.625 & 0.077 \\
Mean (Pl+NC) & 0.18 & -0.20 & 1.23 & 1.00 & 1.33 & 1.28 & -1.09 & 0.31 & -0.08 & 0.23 \\
$\quad(\mathbf{s d})$ & $(0.60)$ & $(0.77)$ & $(0.65)$ & $(0.54)$ & $(0.55)$ & $(0.62)$ & $(0.64)$ & $(0.62)$ & $(0.57)$ & $(0.73)$ \\
\hline
\end{tabular}

statistical significance: $* \mathrm{p}<0.05$

Secondly, we compared epistemology scores between each subpopulation through a T-test (Table 1B). We can notice that with the exception of the esthetical value V1 score, all scores can be assumed as similar. Some means have an absolute value superior to 1 , whereas other means are closer to 0 . The former, clear-cut epistemological scores, concern the positive values associated to scientific knowledge, science, error, teaching and knowledge (V2, V3 and V4) and the negative affects associated to error (A). Relatively to the latter, which does not reflect a shared tendency between individuals, population is more heterogeneous. Positive RTS, C1 and C3 scores means correspond to a dominant positivist and realist epistemology, whereas negative C2 and RWS scores means indicate a constructivist tendency.

V1 score is significantly higher in P1 subpopulation (see Table 2). However, we can notice that all $\mathrm{Pl}$ and $\mathrm{NC}$ subjects have a null or a positive V1 score (not shown), 
which suggests that if the quantity of this value is not comparable, the quality is the same: it is positive. Item per item analysis through Mann-Whitney test indicates that only 4 items among 106 initial items were statistically different between $\mathrm{Pl}$ and NC subpopulations (not shown). Two of those items enter V1 score, one has been excluded from the analysis and the last one is part of V4 score.

We conclude that for all considered scores but V1, NC subpopulation constitutes a satisfying negative control for Pl subpopulation.

\subsection{PI Subpopulation Specific Scores Changes of Answers in the Post-test}

Table 2 shows that only two scores means (RWS and C3) significantly changed in Pl's post-test. For this subpopulation, RWS scores mean is more negative in the posttest than in the pre-test, whereas $\mathrm{C} 3$ scores mean becomes negative in the post-test. Among nine RWS subscale items, six concern the role of a research worker's subjectivity in science (Appendix 1). Moreover, all C3 semantic differentiators focus on subjectivity (or creativity and imagination) relatively to different epistemology objects. So it seems that a major change in players' conception deals with the central role of subjectivity - of subjects - in building knowledge.

Table 2. Evaluation of E+N Specific Effect on Pl and NC Subpopulations Scores

sd : standard deviation

$t$ is obtained following a paired-samples T-test comparing pre-test and post-test scores means for T-test, $\mathrm{df}=13$

statistical significance: $* \mathrm{p}<0.05, * * \mathrm{p}<0.01$

\begin{tabular}{lccccccc}
\hline & \multicolumn{3}{c}{$\mathbf{N C}$} & & \multicolumn{3}{c}{ Pl } \\
\cline { 2 - 3 } $\begin{array}{l}\text { Score } \\
\text { (sd) }\end{array}$ & $\begin{array}{l}\text { Mean at the } \\
\text { pre-test }\end{array}$ & $\begin{array}{l}\text { Mean at the } \\
\text { post-test }\end{array}$ & $\mathbf{t}$ & & $\begin{array}{l}\text { Mean at the } \\
\text { pre-test }\end{array}$ & $\begin{array}{l}\text { Mean at the } \\
\text { post-test }\end{array}$ & t \\
\hline RTS & $0.21(0.68)$ & $0.04(0.65)$ & 1.201 & & $0.15(0.55)$ & $-0.16(0.52)$ & 1.967 \\
RWS & $-0.23(0.78)$ & $-0.56(0.48)$ & 1.469 & & $-0.17(0.79)$ & $-0.72(0.54)$ & $3.016^{* *}$ \\
V1 & $0.93(0.66)$ & $0.81(0.69)$ & 0.563 & & $1.52(0.52)$ & $1.31(0.59)$ & 1.188 \\
V2 & $0.99(0.54)$ & $0.83(0.38)$ & 1.230 & & $1.01(0.56)$ & $0.96(0.53)$ & 0.328 \\
V3 & $1.32(0.60)$ & $1.25(0.54)$ & 0.479 & & $1.35(0.51)$ & $1.29(0.40)$ & 0.359 \\
V4 & $1.14(0.73)$ & $1.10(0.64)$ & 0.268 & & $1.41(0.47)$ & $1.59(0.45)$ & -1.075 \\
A & $-1.14(0.53)$ & $-0.79(0.64)$ & -1.859 & & $-1.04(0.75)$ & $-0.86(0.77)$ & -1.439 \\
C1 & $0.34(0.76)$ & $0.50(0.50)$ & -0.962 & & $0.29(0.47)$ & $0.09(0.61)$ & 1.129 \\
C2 & $-0.01(0.68)$ & $-0.11(0.56)$ & 0.490 & $-0.15(0.46)$ & $-0.25(0.33)$ & 0.766 \\
C3 & $0.22(0.67)$ & $0.00(0.49)$ & 1.223 & & $0.25(0.80)$ & $-0.32(0.56)$ & $2.543 *$ \\
\hline
\end{tabular}

Item per item analysis revealed only few differences between Pl post-test and pretest answers (Table 3). We can notice that among seven significantly changing items, four deal with subjectivity (Q2, Q4, D1, D3), and always in the sense of enhancing subjectivity integration in their conceptions. The fact that Q2 and Q4 are part of RTS score reinforces the previous result obtained with RWS score (Table 2). An interesting result is obtained with Q1 item; it seems that the game has convinced a third of players (not shown) that an isolated research worker cannot do science. 
Table 3. Evaluation of E+N Specific Effect on Pl and NC Subpopulations Item Answers

\begin{tabular}{lcccccccc}
\hline & & \multicolumn{3}{c}{$\mathbf{N C}$} & & \multicolumn{3}{c}{ Pl } \\
\cline { 3 - 4 } \cline { 7 - 9 } & & $\begin{array}{c}\text { Mean at } \\
\text { the pre-test }\end{array}$ & $\begin{array}{c}\text { Mean at the } \\
\text { post-test }\end{array}$ & $\mathbf{Z}^{\mathbf{b}}$ & & $\begin{array}{c}\text { Mean at the } \\
\text { pre-test }\end{array}$ & $\begin{array}{c}\text { Mean at the } \\
\text { post-test }\end{array}$ & $\mathbf{Z}^{\mathbf{b}}$ \\
\hline Q1 & -0.026 & $0.71(1.49)$ & $0.29(1.59)$ & -1.540 & & $0.69(1.70)$ & $-0.57(1.40)$ & $-2.401^{*}$ \\
Q2 & -0.951 & $0.31(1.38)$ & $0.07(1.27)$ & -0.666 & & $0.79(1.58)$ & $-0.38(1.04)$ & $-2.476^{*}$ \\
Q3 & -0.171 & $-1.46(0.88)$ & $-1.21(0.70)$ & -1.000 & & $-1.57(0.64)$ & $-0.86(1.17)$ & $-2.309^{*}$ \\
Q4 & -1.278 & $-1.08(1.32)$ & $-1.14(1.03)$ & -0.520 & & $-0.29(1.64)$ & $-1.36(0.84)$ & $-2.324^{*}$ \\
D1 & -0.025 & $0.36(1.08)$ & $0.14(0.53)$ & -0.918 & & $0.38(1.04)$ & $-0.57(1.09)$ & $-2.220^{*}$ \\
D2 & -1.524 & $0.36(0.84)$ & $0.07(0.73)$ & -1.265 & & $-0.29(1.20)$ & $0.64(1.01)$ & $-2.804^{* *}$ \\
D3 & -1.135 & $-0.21(1.12)$ & $0.14(1.03)$ & -0.905 & & $0.29(0.99)$ & $-0.50(1.02)$ & $-1.995^{*}$ \\
\hline
\end{tabular}

${ }^{a}$ Mann-Whitney test variable is issued from comparison of Pl and $\mathrm{NC}$ answers at the pre-test.

${ }^{\mathrm{b}} \mathrm{Z}$ is issued from Wilcoxon signed ranks test on paired samples comparing pre-test and posttest items answers means. All items of initial experiment that present a significant difference between $\mathrm{Pl}$ and $\mathrm{NC}$ subpopulations at the post-test are presented here.

Q1: "An isolated research worker can do science." Po. Q2: "Scientific theories are inventions." Co (RTS). Q3: "There is always more than one way to interpret an experiment result." Co (RTS). Q4: "Researchers do not use their beliefs to do science" Po. D1: "scientific knowledge": subjective/objective (C3). D2: error; awful-beautiful. D3: learning; subjective/objective.

$P o$ indicates that a total agreement is counted as +2 and $C o$ that the answer is reversed (total agreement as -2). When the item enters a scale, it is mentioned (Q1, Q4, D2 and D3 have not been retained in the scales presented in this paper).

Another promising result concerns D2; to players, error has significantly become more beautiful. This is the only result of our study concerning the change of a value after playing E+N. Finally, an unexpected result is found in Q3 answers change.

\subsection{Putative PI Subpopulation Specific Changes of Conceptions}

Answers to additional open questions (Table 4) indicate that our expectations concerning the occurrence of the term publication - which corresponds to $\mathrm{E}+\mathrm{N}$ nomenclature - in subpopulation Pl have not been satisfied : not only did Pl subjects mention article instead of publication, but they also did it nearly as much as NC subjects. Also, refutation is not mentioned. The only two clear-cut answers specific to subpopulation $\mathrm{Pl}$, which were not predicted, are discussion and subjective. As these questions were not in the pre-test, we cannot be sure that this specificity appeared through the game. However, this result contributes to reinforce previous ones concerning subjectivity and the role of community in science.

Specific OSD relative to proof and refutation in the post-test (Table 5) indicate that proof is significantly more relative, temporary, statistic and collective for Pl than NC subjects. Again for Pl subjects, both proof and refutation are more collective, experimental and complex. It is tempting to think that this corresponds to a game effect. Item per item analysis (not shown) reveals that changes concern complexity for both proof and refutation and on the experimental property of refutation. 
Table 4. Number of Five Selected Terms' Occurrence and Number of Subjects Concerned by these Occurrences in Answers to both Additional Open Questions in the Post-test

\begin{tabular}{lccccc}
\hline & \multicolumn{2}{c}{$\mathrm{NC}$} & & \multicolumn{2}{c}{$\mathrm{Pl}$} \\
\cline { 2 - 3 } \cline { 5 - 6 } \cline { 5 - 6 } & $\mathrm{N}$ (occurrence) & $\mathrm{N}$ (subjects) & & $\mathrm{N}$ (occurrence) & $\mathrm{N}$ (subjects) \\
\hline article $_{\text {eurêka }^{\mathrm{b}}}$ & 4 & 3 & & 5 & 5 \\
experiment $^{\mathrm{a}, \mathrm{b}}$ & 1 & 1 & & 1 & 1 \\
discussion & 3 & 3 & & 3 & 3 \\
subjective $^{\mathrm{a}}$ & 0 & 1 & & 6 & 5 \\
\hline
\end{tabular}

a or related term : experimentation, subjectivity, ...

${ }^{\mathrm{b}}$ both terms are chosen as negative controls and were not particularly expected.

Discussion is the term with the highest overall occurrence. Other terms which are not indicated here are very disparate and seem to come under heterogeneous categories.

Table 5. Comparison of $\mathrm{Pl}$ and NC Additional OSD Post-test Scores Means

\begin{tabular}{llll}
\hline & $\mathrm{RePr}$ & $\mathrm{Re}$ & $\operatorname{Pr}$ \\
\hline NC score mean (sd) & $-0.21(0.30)$ & $-0.11(0.49)$ & $0.11(0.57)$ \\
$\mathrm{Pl}$ score mean (sd) & $-0.91(0.55)$ & $-0.07(0.87)$ & $-0.33(0.48)$ \\
$\mathrm{t}(\mathrm{NC} v s \mathrm{Pl})$ & $-4.201 * * *$ & 0.134 & $-2.124^{*}$ \\
\hline
\end{tabular}

sd : standard deviation

$t$ is issued from independent samples T-test

statistical significance : *** $\mathrm{p}<0.0005, * \mathrm{p}<0.05$

\section{Discussion}

\subsection{Population Initial Epistemology}

We proposed a pre-test and a post-test to students who played $\mathrm{E}+\mathrm{N}$ for two hours and we compared changes in answers with the ones of negative controls (non-players). The test evaluates conceptions, values and affects concerning scientific process.

Before the game, initial Pl's and NC's epistemology where similar, except from esthetical values, which were higher for Pl. This heterogeneity effect underlies a limit of our study: the smallness of our samples. Future experiment will be done with greater samples. Otherwise, positive values were expected from students who aim to become science teachers. The negative affective dimension of attitude towards error had already been characterized [7] and is explained, together with general conception tendencies elsewhere [10]. Slightly negative scores means (RWS and C2) - indicating constructivist conceptions - are interpreted as concerning on-going science: these students know that error takes part of science and that scientists can have "wrong" interpretations or theories. But they think that once the error is detected, knowledge which is kept is true. This last point would explain slightly positive scores means (RTS, C1 and C3) and correspond to a realist and positivist point of view.

\subsection{Conception Change Through E+N Playing}

We tried to evaluate several aspects linked to constructivism. Among these, the aspect which is recurrently and significantly changed - specifically to $\mathrm{Pl}$ - concerns the role 
of subjectivity in scientific process. These results are reinforced by those obtained with additional specific post-test questions. Additionally, Q1 item and answers that indicate putative conception changes focus on the role of community in scientific process. Thus, to us, the game allowed Pl to become aware of these central aspects of constructivism, so that they specifically assimilated them in the cognitive components of their epistemic attitudes. The only one result which was not predicted is the change of Q3 answer; Pl are in fact less likely to believe that several interpretations are possible in front of a given result. Maybe they assimilated possible, in the sense of what a research worker can propose, with right, in the sense of what is acceptable given a theory. This could be due to the strict formalism of the game, in which theories are predetermined and perfectly knowledgeable.

Because of the difficulty to find volunteers, we organised this experiment with our students, who were supposed to follow epistemology courses. This could explain why NC's scores also change between the pre-test and the post-test. However, statistics give us a clear limit and the significance levels that we use are absolutely standard. So no statistically significant score change has been observed in NC subpopulation.

\subsection{Suitability of the Game for Epistemology Teaching}

In the game, hidden rules represent what would be in reality "facts resistance to experimentation". Thus, the conventional law constructed by players' community do not necessarily correspond to the hidden rule. In that way, the game partly modelises construction of knowledge by a research worker community. Although we did not wanted that auto-refutation could allow point winnings, we noticed that this could modelise an existing scientific strategy. It is possible that this parameter greatly influenced $\mathrm{Pl}$ in their consideration of science as relying on subjectivity; the one who wins can do it through cheating! As all observed answers changes do not focus on themes that are explicitly dealt with in the game, but just practiced, we infer that this constructivist conception has been subconsciously assimilated, in the Piagetian sense. We cannot exclude that this effect occurred synergistically with traditional epistemology courses. Even so, observed changes are very encouraging, because they would have been caused by only two hours of playing.

An important factor for such a teaching tool is users' pleasure. Open questions in the post-test treated of the matter of feelings during playing (not shown). We noticed that answers extremely differed: either players liked it much, or they got "very frustrated because of cheats". This highlights what we also observed during the game: they really got involved into it. Previous experiments with 13 or 20-year-old pupils lead to the same conclusion. When time was out, a majority was disappointed and wanted to continue (that rarely happens with a traditional course!).

Altogether, it indicates that $\mathrm{E}+\mathrm{N}$ game can constitute a very interesting complementary tool to teach epistemology. In this report, we did not address the evaluation of what ability players learn through the game. It would be interesting to evaluate students' skills to apply the refutation principle, to manipulate hypothesis and to propose experiences in front of a problem. We shall go deeper into this question, which will be dealt with in future investigations. 


\section{References}

1. Bachelard, G.: Epistémologie (1971). Presses Universitaires de France (2001)

2. Boulton-Lewis, G.M., Smith, D.J.H., McCrindle, A.R., Burnett, P.C., Campbell, K.J.: Secondary Teachers' Conceptions of Teaching and Learning. Learn. Instr. 11, 35-51 (2001)

3. Bulletin Officiel: Les compétences professionnelles des maîtres. MENS0603181A (2007)

4. Chan, K.-W., Elliott, R.G.: Relational Analysis of Personal Epistemology and Conceptions About Teaching and Learning. Teach. Teach. Educ. 20, 817-831 (2004)

5. Chavalarias, D.: La thèse de Popper est-elle réfutable? Mémoire de DEA CREACNRS/Ecole Polytechnique (1997)

6. Dartnell, C., Sallantin, J.: Assisting Scientific Discovery with an Adaptive Problem Solver. Discov. Sci. (2005)

7. Favre, D.: Conception de l'erreur et rupture épistémologique. Rev. Fr. Pédagog 111, 85-94 (1995)

8. Fourez, G., Englebert-Lecomte, V., Mathy, P.: Nos savoirs sur nos savoirs, DeBoeck Université (1997)

9. Gardner, M.: Mathematical Games. Sci. Am. (1959)

10. Hagége, H.: Jugement de valeurs, affects et conceptions sur lélaboration du savoir scientifique: á la recherche d'obstacles á l'enseignement des questions vives. In: Giordan, A., Martinand, J.-L. (eds.) XXVIII ${ }^{\text {émes }}$ journées internationales sur la communication, léducation et la culture scientifiques, techniques et industrielles (under press, 2007)

11. Hagège, H., Reynaud, C., Caussidier, C., Favre, D.: New Conceptualisation of Environmental Attitudes: Cut, Relatedness and Fusion Towards the Nonhuman Environment - Preliminary Measure. Environ. Behav. (submitted)

12. Howard, B.C., McGee, S., Schwartz, N., Purcell, S.: The Experience of Constructivism: Transforming Teacher Epistemology. J. Res. Comput. Educ. 32, 455-465 (2000)

13. Klahr, D., Dunbar, K.: Dual Search Space During Scientific Reasoning. Cogn. Sci. 12, 148 (1988)

14. Kuhn, T.: La structure des révolutions scientifiques. Champs Flammarion (1962)

15. Lederman, N.G., Abd-El-Khalick, F., Bell, R.L., Schwartz, R.S.: Views of Nature of Science Questionnaire: Toward Valid and Meaningful Assessment of Learners' Conceptions of Nature of Science. J. Res. Sci. Teach. 39, 497-521 (2002)

16. Lemberger, J., Hewson, P.W., Park, H.-J.: Relationships between Prospective Secondary Teachers' Classroom Practice and Their Conceptions of Biology and of Teaching Science. Sci. Educ. 83, 347-371 (1999)

17. Lonka, K., Joram, E., Brysin, M.: Conceptions of Learning and Knowledge: Does Training Make a Difference? Contemp. Educ. Psychol. 21, 240-260 (1996)

18. Schommer, M.: Synthesizing Epistemological Belief of Research: Tentative Understandings and Provocative Confusions. Educ. Psychol. Rev. 6, 293-319 (1994)

19. Strike, K.A., Posner, G.J.: A Revisionist Theory of Conceptual Change. In: Duschl, R.A., Hamilton, R.J. (eds.) Philosophy of Science, Cognitive Psychology, and Educational Theory and Practice, pp. 147-176 (1992)

20. Waeytens, K., Lens, W., Vandenberghe, R.: Learning to Learn: Teachers Conceptions of Their Supporting Role. Learn. Instr. 12, 305-322 (2002)

21. Zimmerman, C.: The Development of Scientific Reasoning Skills. Dev. Rev. 20, 99-149 (2000) 


\section{Appendix}

For OSD and questionnaires, we proposed, for each item, five intermediate possible choices. As our test is prospective, and given the small size of our samples, we calculated scores. Principal Components Analysis (PCA) was made on initial experiment results to check and if necessary uncover items that seemed to measure the same dimension. Based on these results, we grouped correlated items into scales and checked again the internal consistency of these scales by calculating the Cronbach's $\alpha$.

\section{A.1 Composition of Questionnaire Subscales Used in Pre-test and Post-test}

The questionnaire used for initial experiment $(\mathrm{N}=43)$ questionnaire was composed of 39 items. Based on these results, we chose 19 items which constitute a robust scale (Chronbach's $\alpha=0.823$ ). PCA allowed to distinguish two subscales. We named the subscales according to repartition specificity of observed items, although each subscale also contains items assessing comparable themes.

\begin{tabular}{|ll|}
\hline \multicolumn{1}{|c|}{ Research Worker Status (RWS) Subscale } \\
\hline Po & Objectivity is intrinsic to scientific activity. \\
Co & Subjectivity is intrinsic to scientific activity. \\
Po & Scientific progress consists in a gradual accumulation of knowledge. \\
Po & Every scientific observation is neutral. \\
Po & Every scientific observation is objective. \\
Co & Every scientific theory is likely to be questioned in the future. \\
Po & Research workers do not use their beliefs to do science. \\
Po & If an experimental result is not compatible with a scientific theory, then this theory will \\
& necessarily be questioned. \\
Co & Even advice from experts should often be questioned. ${ }^{\text {a }}$ \\
\hline & \multicolumn{1}{c|}{ Realism and Truth Status (RTS) Subscale } \\
\hline Po & Science produces knowledge which progressively accumulates. \\
Co & Scientific theories are inventions. \\
Co & The notion of atom is an invention. \\
Po & The notion of atom is a discovery. \\
Po & The result of an experimentation imposes a conclusion. \\
Co & There are always several possible interpretations for an experimental result. \\
Po & There is some scientific knowledge considered as acquired and which will never be \\
& questioned. \\
Po & We can say about a part of scientific knowledge that it is true. \\
Po & Before, there were theories which were false, but now we tend more and more towards truth. \\
Co & Sometimes I don't believe the facts in textbooks written by authorities. \\
\hline
\end{tabular}
one. Answers are counted as follow:

\begin{tabular}{l|l|c|c|c|c|c|l|} 
Po item : & Agree & 2 & 1 & 0 & -1 & -2 & Disagree \\
\hline Co item : & Agree & -2 & -1 & 0 & 1 & 2 & Disagree \\
\hline
\end{tabular}

For each subscale and each student, we calculate a score between -2 (constructivist/idealist extremity) and +2 (positivist/realist, i.e. nä̈ve extremity), 
which is their average answers to corresponding subscale items. Chronbach's $\alpha$ of RWS and RTS subscales are 0.750 and 0.738 , respectively.

\section{A.2 Composition and Internal Consistency of Osgood's Semantic Differentiators (OSD) Subscales of Pre-test and Post-test}

We classified antagonistic adjectives into three registers. We refer to explicit register of values, conceptions and affects because we made the a priori hypothesis that this adjectives mostly appeal to the corresponding dimension. However, no term has a pure connotation.

A) Composition of V1, V2, V3, V4, A, C1, C2 and C3 subscales

\begin{tabular}{|c|c|c|c|c|c|c|}
\hline \multicolumn{2}{|c|}{$\begin{array}{l}\text { Items } \\
\text { Explicit register of values }\end{array}$} & $\begin{array}{l}\text { scientific } \\
\text { knowledge }^{a}\end{array}$ & science & error & teaching & knowledge $^{\mathrm{b}}$ \\
\hline $\begin{array}{l}\text { negative pole }( \\
\text { 2) }\end{array}$ & $\begin{array}{l}\text { positive pole } \\
(+2)\end{array}$ & \multirow{3}{*}{ V1 } & & & \multirow{3}{*}{ V1 } & \multirow{3}{*}{ V4 } \\
\hline awful & beautiful & & V1 & & & \\
\hline false & true & & $\mathrm{V} 2$ & & & \\
\hline bad & good & $\mathrm{V} 2$ & $\mathrm{~V} 2$ & V3 & V3 & V4 \\
\hline negative & positive & & & V3 & & V3 \\
\hline useless & useful & & & $\mathrm{V} 2$ & & V3 \\
\hline not interesting & interesting & & & V3 & & V4 \\
\hline \multicolumn{7}{|c|}{ Explicit register of affects } \\
\hline painful & pleasant & & & A & & V4 \\
\hline scaring & tempting & & & A & & V4 \\
\hline \multicolumn{7}{|c|}{ Explicit register of conceptions } \\
\hline $\begin{array}{l}\text { non dogmatic } \\
\text { pole }(-2)\end{array}$ & $\begin{array}{l}\text { dogmatic } \\
\text { pole }(+2)\end{array}$ & & & \multirow{6}{*}{$\mathrm{C} 2$} & \multirow{9}{*}{$\mathrm{C} 3$} & \multirow{6}{*}{$\mathrm{C} 2$} \\
\hline \multirow{8}{*}{$\begin{array}{l}\text { approximate } \\
\text { imprecise } \\
\text { contextual } \\
\text { relative } \\
\text { temporary } \\
\text { subjective } \\
\text { stemming from } \\
\text { imagination } \\
\text { created }\end{array}$} & exact & $\mathrm{C} 1$ & $\mathrm{C} 1$ & & & \\
\hline & precise & $\mathrm{C} 1$ & $\mathrm{C} 1$ & & & \\
\hline & universal & $\mathrm{C} 2$ & $\mathrm{C} 2$ & & & \\
\hline & absolute & $\mathrm{C} 2$ & & & & \\
\hline & definitive & $\mathrm{C} 2$ & & & & \\
\hline & objective & $\mathrm{C} 3$ & $\mathrm{C} 2$ & $\mathrm{C} 3$ & & $\mathrm{C} 3$ \\
\hline & $\begin{array}{l}\text { stemming } \\
\text { from reason }\end{array}$ & $\mathrm{C} 3$ & & & & \\
\hline & given & $\mathrm{C} 3$ & & & & \\
\hline
\end{tabular}

On an initial amount of 42 differentiators, comprising 3 types of explicit registers, we kept this 37 differentiators. From initial experiment, they were shown by PCA to be organized into two values groups and two conceptions groups, except for error affects which where apart. Then we defined, through two other PCA (one for values and one for conceptions), subgroups of differentiators for each category. We can notice that explicit registers of knowledge affects work as knowledge specific values. Apart from these last differentiators and for those we removed, our a priori explicit registers were consistent. 
B) Internal Consistency (Chronbach's $\alpha$ )

\begin{tabular}{ccccccccc}
\hline subscale & $\mathrm{V} 1$ & $\mathrm{~V} 2$ & $\mathrm{~V} 3$ & $\mathrm{~V} 4$ & $\mathrm{~A}$ & $\mathrm{C} 1$ & $\mathrm{C} 2$ & $\mathrm{C} 3$ \\
\hline$\alpha$ & 0.7494 & 0.7126 & 0.6853 & 0.7239 & 0.5837 & 0.7034 & 0.7137 & 0.6844 \\
\hline
\end{tabular}

\section{A.3 Composition and Internal Consistency of Post-test Specific OSD Subscales}

\begin{tabular}{|c|c|c|c|}
\hline \multicolumn{2}{|c|}{ explicit register of conceptions } & \multirow[t]{2}{*}{ proof } & \multirow[t]{2}{*}{ Refutation } \\
\hline non dogmatic pole $(-2)$ & dogmatic pole $(+2)$ & & \\
\hline relative & absolute & $\operatorname{Pr}$ & \\
\hline temporary & definitive & $\operatorname{Pr}$ & $\operatorname{Re}$ \\
\hline statistic & $\operatorname{logic}$ & $\operatorname{Pr}$ & $\operatorname{Re}$ \\
\hline collective & individual & $\operatorname{Pr}$ & $\operatorname{RePr}$ \\
\hline experimental & theoretical & $\operatorname{RePr}$ & $\operatorname{RePr}$ \\
\hline complex & simple & $\operatorname{RePr}$ & $\operatorname{RePr}$ \\
\hline
\end{tabular}

B) Internal Consistency

\begin{tabular}{cccc}
\hline subscale & $\operatorname{Pr}$ & $\operatorname{Re}$ & $\operatorname{RePr}$ \\
\hline Chronbach's $\alpha$ & 0.4179 & 0.6047 & 0.4267 \\
\hline
\end{tabular}

